\title{
UCRL-TR-208623
}

LAWRENCE LIVERMORE N A T IO N A L LABORATORY

\section{Advancing Climate and Carbon Simulation}

S. Thompson

December 15, 2004 


\section{Disclaimer}

This document was prepared as an account of work sponsored by an agency of the United States Government. Neither the United States Government nor the University of California nor any of their employees, makes any warranty, express or implied, or assumes any legal liability or responsibility for the accuracy, completeness, or usefulness of any information, apparatus, product, or process disclosed, or represents that its use would not infringe privately owned rights. Reference herein to any specific commercial product, process, or service by trade name, trademark, manufacturer, or otherwise, does not necessarily constitute or imply its endorsement, recommendation, or favoring by the United States Government or the University of California. The views and opinions of authors expressed herein do not necessarily state or reflect those of the United States Government or the University of California, and shall not be used for advertising or product endorsement purposes.

\section{Auspices Statement}

This work was performed under the auspices of the U. S. Department of Energy (DOE) by the University of California, Lawrence Livermore National Laboratory (LLNL) under Contract No. W-7405-Eng-48. The project (04-ERD-051) was funded by the Laboratory Directed Research and Development Program at LLNL. 


\title{
FY04 LDRD Final Report Advancing Climate and Carbon Simulation LDRD Project Tracking Code: 04-ERD-051 Starley Thompson, Principal Investigator
}

\begin{abstract}
We use a recently developed integrated climate/carbon model to perform breakthrough studies of the climate. Two major studies are carried out - namely the effects of $\mathrm{CO}_{2}$ fertilized vegetation on global climate and carbon dynamics, and the effect of climate sensitivity on carbon cycle feedback. We have also begun development of a nextgeneration climate/carbon modeling capability.
\end{abstract}

\section{Introduction/Background}

Atmospheric $\mathrm{CO}_{2}$ concentrations are prescribed, not simulated, in operational large climate models. To assess impacts of fossil fuel burning, however, we need to predict time-evolving atmospheric greenhouse forcing using anthropogenic emissions as the fundamental input. Predicting atmospheric $\mathrm{CO}_{2}$ concentrations represents a substantial scientific advance because large terrestrial biospheric and oceanic sources/sinks of carbon are key components of the present-day carbon cycle that will change in the future. Models driven by prescribed greenhouse gas emission rates (not concentrations) are needed to assess impacts of proposed emission policies. The successful work of the INCCA (INtegrated Climate and CArbon) Strategic Initiative has given LLNL such a comprehensive climate-carbon simulation capability.

This Exploratory Research project, denoted Advancing Climate and Carbon Simulation (ACCS), is a one-year effort to build on, and advance beyond, the work of the INCCA project. The intent is to fully realize scientific return, upgrade simulation codes, and improve the science of key sub-systems so that we can best position LLNL for external support. We now have a capability in comprehensive coupled climate-carbon simulation

that is the best in the nation. Through this effort we insure that this capability is exploited and improved to keep us at the forefront.

This report consists of several parts. In section 2 we describe the computational model. We then discuss two scientific experiments: In section 3 we examine the effects of $\mathrm{CO}_{2}-$ fertilized vegetation on global climate and carbon dynamics, and in section 4 we examine the carbon cycle feedback as a function of climate sensitivity. In section 5 we discuss model improvements for future simulations. The exit plan is given in section 6 . A summary is presented in Section 7, and the references are given in Section 8.

\section{Computational Model}

The INCCA model consists of several components. The physical ocean-atmosphere 
model is the NCAR/DOE PCTM model (Meehl et al., 2004; Washington et al., 2000), which is a version of the NCAR CCM 3.2 model (Kiehl et al., 1996) coupled to the LANL POP ocean model (Dukowicz and Smith, 1994; Maltrud et al., 1998). The climate model is coupled to a terrestrial biosphere model, Integrated Biosphere Simulator (IBIS) version 2 (Foley et al., 1996; Kucharik et al., 2000) and an ocean biogeochemistry model. The horizontal resolution of the land and atmosphere models is approximately $2.8^{\circ}$ in latitude and $2.8^{\circ}$ in longitude. The ocean model has a horizontal resolution of $(2 / 3)^{\circ}$. The atmosphere and ocean models have 18 and 40 levels in the vertical, respectively.

Land surface biophysics, terrestrial carbon flux and global vegetation dynamics are represented in a single, physically consistent modeling framework within IBIS. IBIS simulates surface water, energy and carbon fluxes on hourly time steps and integrates them over the year to estimate annual water and carbon balance. IBIS also simulates carbon cycling through litter and soil organic matter. We have parallelized IBIS to support both distributed and shared memory parallelism. The land points are partitioned among tasks in a load-balanced manner, with high-speed transposes used to connect the land and atmospheric domain decompositions. Further details are provided in Thompson, et al. (2004).

The ocean biogeochemistry model is based on the Ocean Carbon-cycle Intercomparison Project (OCMIP) Biotic protocols (Najjar and Orr, 1999). This model predicts air-sea $\mathrm{CO}_{2}$ fluxes, biogenic export of organic matter and calcium carbonate, and distributions of dissolved inorganic carbon, phosphate, oxygen, alkalinity, and dissolved organic matter. In the OCMIP protocol, export of biogenic materials is computed to maintain observed upper ocean nutrient concentrations. However, because our simulations involve changes in ocean circulation, we cannot make the assumption that surface nutrient concentrations remain stationary. Therefore, we replaced the OCMIP export formulation with a formulation based on that of Maier-Reimer (1993).

\section{3. $\mathrm{CO}_{2}$-Fertilized Vegetation Effects}

The magnitudes of feedbacks within the climate-carbon system are poorly constrained. Higher $\mathrm{CO}_{2}$ concentrations increase photosynthesis and promote water-use and nitrogenuse efficiency of plants, ultimately increasing plant growth (Houghton, et al., 2001). Biomass and soil carbon, and thus terrestrial carbon uptake, may be expected to increase with higher atmospheric $\mathrm{CO}_{2}$ levels. However, the effects of photosynthetic $\mathrm{CO}_{2}$ "fertilization" will saturate at sufficiently high $\mathrm{CO}_{2}$ levels (Farquhar, et al., 1980; Houghton, et al., 2001), and higher global temperatures may increase the loss of soil carbon to the atmosphere (Giardina and Ryan, 2000; Houghton, et al., 2001; Lloyd and Taylor, 1994).

Results from two recent modeling studies, referred to here as Hadley (Cox, et al., 2000) and IPSL (Friedlingstein, et al., 2001), led to different conclusions regarding the role of the land biosphere in future global change. In the Hadley simulation, the land biosphere becomes a net source of $\mathrm{CO}_{2}$ to the atmosphere by year 2050, whereas in the IPSL simulation, it remains a net sink throughout the $21^{\text {st }}$ century. We show that we can 
produce a change of sign in biospheric response by changing only one assumption in a fully coupled three-dimensional model: whether $\mathrm{CO}_{2}$-fertilization rapidly saturates in terrestrial ecosystems. A summary of results is presented here. More comprehensive information can be found in Thompson, et al. (2004).

We integrate the fully coupled model to quasi-equilibrium to form a year 1870 preindustrial initial condition that is used as the starting point for three model cases. The "control" case has no $\mathrm{CO}_{2}$ emissions and thus no change in radiative forcing for the period 1870-2100. Model drift for the control case over years 1900 to 2100 is $-0.35 \mathrm{~K}$ in mean surface temperature and $+3.14 \mathrm{ppmv}$ in atmospheric $\mathrm{CO}_{2}$. Both are minimal residuals from an imbalance in the initial state and are not subtracted from the other simulations in our analysis.

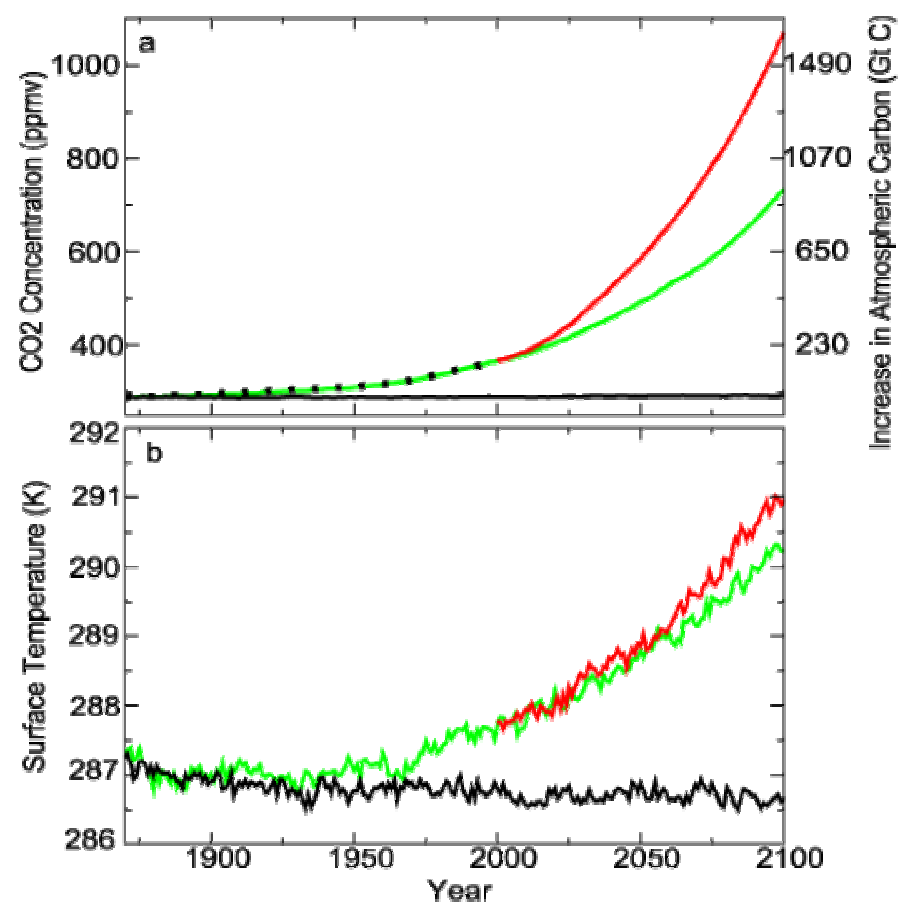

Figure 1. Simulated atmospheric $\mathrm{CO}_{2}$ and global mean surface temperature from 1870 to 2100. (a) $\mathrm{CO}_{2}$ for the control (black), fertilization (green), and saturation (red) cases. Black dots are observed $\mathrm{CO}_{2}$ concentrations. If $\mathrm{CO}_{2}$ fertilization saturates early, the landbiosphere becomes a net source of $\mathrm{CO}_{2}$ to the atmosphere, adding to anthropogenic $\mathrm{CO}_{2}$ emissions. (b) Temperature for the same cases as (a).

The "fertilization" case has $\mathrm{CO}_{2}$ emissions specified at historical levels (Marland, et al., 2000) for 1870-2000 and that follow the IPCC scenario (Houghton, et al., 2001) SRES A2 from 2000-2100. Non- $\mathrm{CO}_{2}$ greenhouse gas concentrations are specified at historical levels for 1870-2000 and SRES A2 level from 2000-2100. Land use emissions are reconstructions (Houghton, 2003) for the historical period and from the SRES A2 scenario thereafter. In this scenario, total emissions reach 29 Gigatons carbon (GtC) per year in year 2100 from present day values of $8 \mathrm{GtC}$ per year. 
The "saturation" case is identical to the fertilization case except the $\mathrm{CO}_{2}$ fertilization is assumed to saturate at the year 2000 concentration, accomplished by forcing the terrestrial biosphere model with a constant $\mathrm{CO}_{2}$ concentration of 366 ppmv after year 2000 .

Figure 1a shows that assumptions regarding $\mathrm{CO}_{2}$-fertilization of the land biosphere greatly affect the atmospheric concentration of $\mathrm{CO}_{2}$. Year 2100 atmospheric $\mathrm{CO}_{2}$ concentrations are 336 ppmv higher in the saturation case than in the fertilization case. In the SRES A2 scenario, $1790 \mathrm{GtC}$ is emitted to the atmosphere over the $21^{\text {st }}$ century; atmospheric $\mathrm{CO}_{2}$ content increases by $776 \mathrm{GtC}(366 \mathrm{ppmv})$ and $1489 \mathrm{GtC}$ (702 ppmv) in our fertilization and saturation cases, respectively. The temperature difference at year 2100 between the saturation and fertilization cases is only $0.7 \mathrm{~K}$ (Fig. 1b).

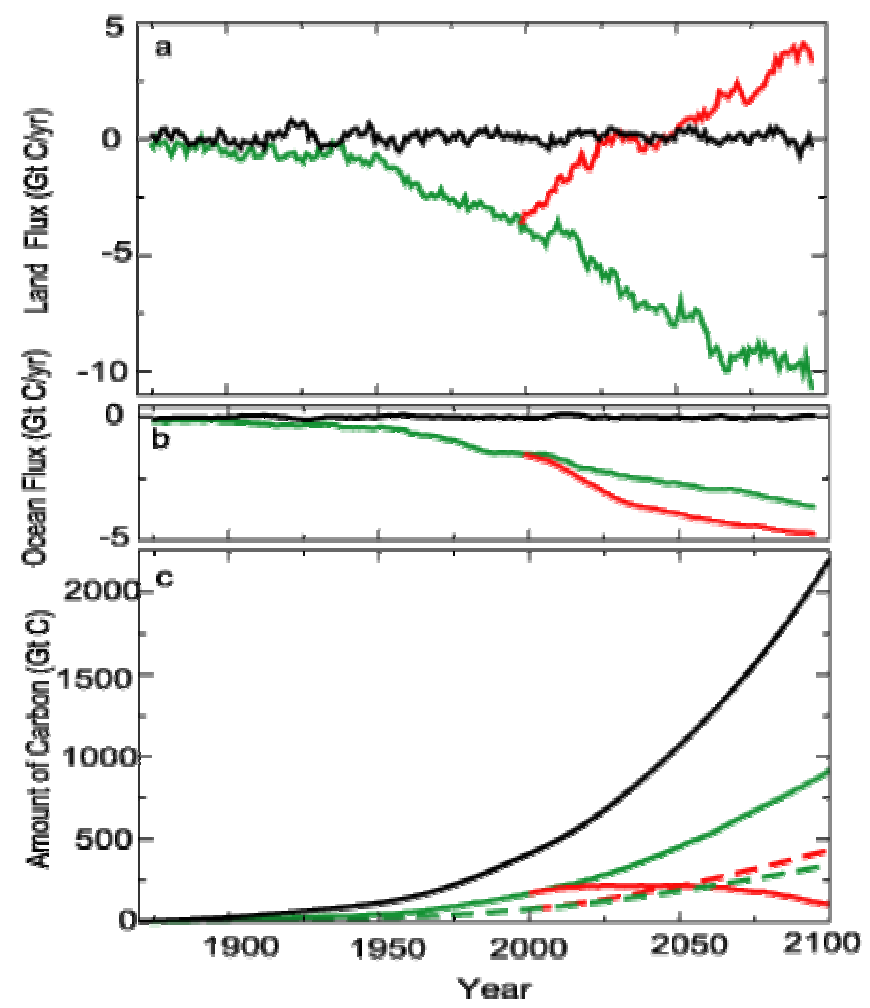

Figure 2. Global carbon fluxes and carbon inventory change from 1870 to 2100. (a) Flux of carbon from land to atmosphere. Control (black), fertilization (green), and saturation (red) cases. In the saturation case the land becomes a net source of carbon by year 2050 . (b) The same as (a) but for carbon flux from ocean to atmosphere. (c) Global carbon change from the 1870 pre-industrial starting point. Total earth system (black), land (solid), and ocean (dashed). Fertilization case (green), and saturation case (red).

Results (Fig. 2a) show that assumptions regarding the saturation of $\mathrm{CO}_{2}$-fertilization can affect the sign of the $\mathrm{CO}_{2}$ flux between the atmosphere and land by century's end. Direct $\mathrm{CO}_{2}$ effects are expected to lead to increased terrestrial carbon uptake, but temperature effects can lead to increased heterotrophic respiration and loss of soil carbon (Cox, et al., 2000; Cramer, et al., 2001; Friedlingstein, et al., 2001; Joos, et al., 2001), at least until a 
possible acclimation of soil microbiology to the higher temperatures (Kirschbaum, 2000; Tjoelker, et al., 2001). In the saturation case, by year 2100 the land-biosphere has become a net source of $\mathrm{CO}_{2}$ to the atmosphere, as temperature effects dominate $\mathrm{CO}_{2}$-fertilization effects. In the fertilization case, $\mathrm{CO}_{2}$-fertilization effects dominate temperature effects, resulting in continued net biospheric growth.

The model's historical ocean carbon uptake of $77 \mathrm{GtC}$ is an underestimate when compared against the recent observational estimates of $118 \mathrm{GtC}$ for the period from 1800 to 1994 (Sabine, et al., 2004). Between year 2000 and year 2100, ocean/atmosphere carbon fluxes show significant differences between the fertilization and saturation cases (Fig. 2b). Ocean carbon storage increases by 269 and $357 \mathrm{GtC}$ in the two cases (Fig 2c). Ocean uptake is greater in the saturation case because increased atmospheric $\mathrm{CO}_{2}$ concentrations drive an increased flux of $\mathrm{CO}_{2}$ from the atmosphere to the ocean that is larger than any counteracting temperature and biogeochemical effects (Sarmiento, et al., 1998). The increase in ocean carbon storage at year 2100 in both the cases is less than 15 $\%$ of the amount that could be stored if the ocean were in equilibrium with the respective year 2100 atmospheric $\mathrm{CO}_{2}$ concentrations (Kheshgi, 2004).

Cumulative carbon emissions since 1870 reach $2200 \mathrm{GtC}$ by year 2100 (Fig. 2c). In the fertilization case, the land biosphere and the oceans sequester $919 \mathrm{GtC}(42 \%)$ and 346 $\mathrm{GtC}(15.5 \%)$ of the total emissions, respectively. In the saturation case, the corresponding amounts are $104 \mathrm{GtC}(5 \%)$ and $435 \mathrm{GtC}(19.5 \%)$. Thus, in our model the variation in land uptake of carbon due to the degree of $\mathrm{CO}_{2}$ fertilization varies from $5 \%$ to $42 \%$ of the total carbon emitted. The carbon remaining in the atmosphere is $935 \mathrm{GtC}(42.5 \%)$ and $1661 \mathrm{GtC}(75.5 \%)$ for the fertilization and saturation cases, respectively.

The results show that the amount of anthropogenic $\mathrm{CO}_{2}$ in the atmosphere at the end of the century will probably be sensitive to carbon-cycle processes about which we are uncertain at present. Right now, the uncertain response of the land biosphere to increased $\mathrm{CO}_{2}$ and climate change prevents us from knowing if terrestrial carbon-cycle feedbacks will damp or amplify global warming.

\section{Climate Sensitivity Effects}

In this study, we address the dependence of terrestrial and ocean carbon uptakes on climate sensitivity. The major purpose is to investigate the sensitivity of carbon cycle feedbacks to climate sensitivity. The climate change range we have studied in this work is $0-8 \mathrm{~K}$ warming of global and annual mean surface temperature by year 2100 for the SRES A2 Scenario (IPCC, 2001). The warming produced here brackets the $1.4-5.8 \mathrm{~K}$ warming for year-2100 projected by IPCC (2001). A summary of results is presented here. More comprehensive information can be found in Govindasamy, et al. (2004).

We perform four model simulations starting from the pre-industrial initial conditions:

(i) "Control" case is the same as in section 3.

(ii) "1 x Sensitivity" case is called the "fertilization" case in the previous section. 
(iii) "0 x Sensitivity" case which is identical to the " $1 \mathrm{x}$ Sensitivity" case except that the radiation model continues to see the pre-industrial atmospheric $\mathrm{CO}_{2}$ content, yielding a climate sensitivity of $0 \mathrm{~K}$ per $\mathrm{CO}_{2}$-doubling; though the land and ocean carbon cycle models are forced by the predicted atmospheric $\mathrm{CO}_{2}$ concentration, the physical climate system is not. Our "0x Sensitivity" case is similar to the uncoupled simulations in Cox, et al. (2000) and Friedlingstein, et al. (2001) except that our simulations are not performed offline.

(iv) "2 $\mathrm{x}$ Sensitivity" case which is identical to the " $1 \mathrm{x}$ Sensitivity" case, except that the radiation model sees an amount of $\mathrm{CO}_{2}$ in the atmosphere that would roughly double the radiative forcing from anthropogenic $\mathrm{CO}_{2}$. The carbon cycle models use the actual predicted $\mathrm{CO}_{2}$. Prescribed non- $\mathrm{CO}_{2}$ greenhouse gas concentrations as seen by the climate system are also modified so that the radiative forcing is approximately twice that of "1 $\mathrm{x}$ Sensitivity". This would be expected to roughly double the climate sensitivity of the model. We do not expect that the radiative forcing and climate change in 2 x Sensitivity will be exactly twice that of the $1 \mathrm{x}$ Sensitivity case for the following two reasons. First, we have used approximate formulae to double the forcings in $2 \mathrm{x}$ Sensitivity. Secondly our results show that the predicted $\mathrm{CO}_{2}$ concentration in $2 \mathrm{x}$ Sensitivity is slightly higher than in $1 \times$ Sensitivity.

The main purpose of these experiments is to provide a set of coupled climate/carboncycle simulations across which the only varying factor is climate sensitivity to increased atmospheric $\mathrm{CO}_{2}$ concentrations. By keeping all other factors constant, we simplify analysis of our results.

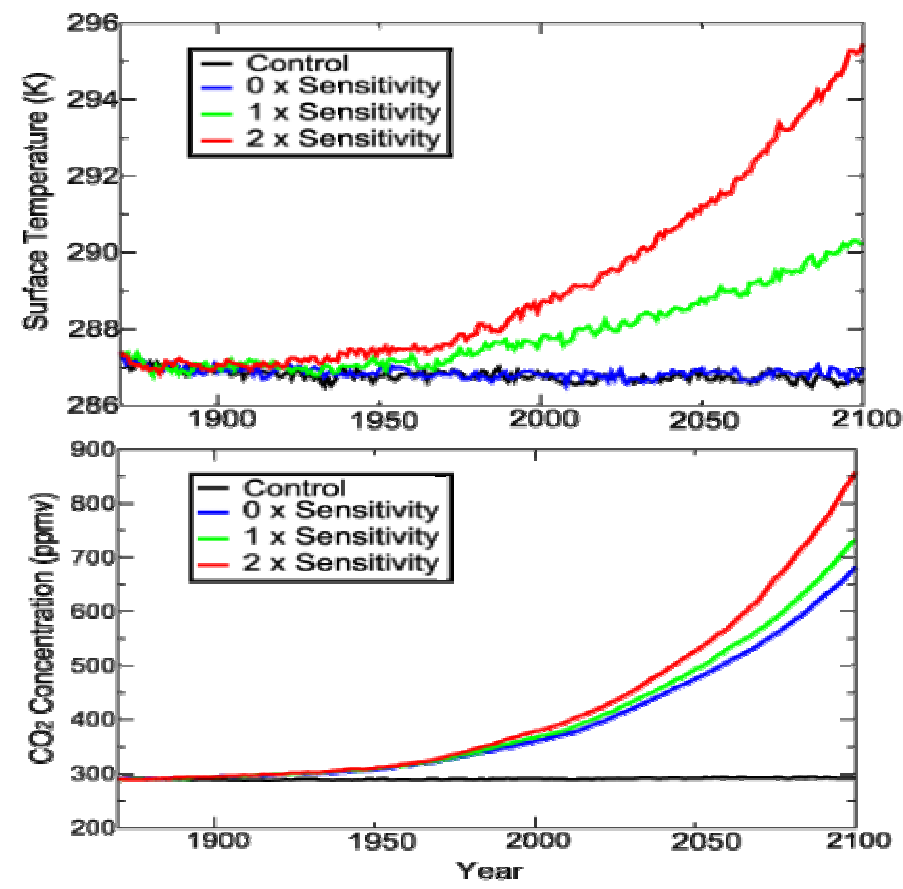

Figure 3 Evolution of global and annual mean surface temperature (upper panel) and atmospheric $\mathrm{CO}_{2}$ concentration (lower panel). 
The evolution of global and annual means of surface temperature and atmospheric $\mathrm{CO}_{2}$ concentration from the four simulations is shown in Fig. 3. The climate does not warm in the $0 \times$ Sensitivity experiment, warms by about $3.2 \mathrm{~K}$ in the $1 \times$ Sensitivity experiment, and by $8 \mathrm{~K}$ in the $2 \mathrm{x}$ Sensitivity case. The warming in the $2 \mathrm{x}$ Sensitivity run is 2.5 times that in the $1 \mathrm{x}$ Sensitivity run, indicating that the climate response is approximately proportional to radiative forcing. Changes in other global variables such as precipitation, precipitable water and sea ice extent in the $2 \times$ Sensitivity case are also more than twice the changes in the $1 \mathrm{x}$ Sensitivity case. In the $2 \times$ Sensitivity case, there is a decline of nearly $95 \%$ of ice volume. We find that the sea ice disappears completely in both hemispheres in their respective summers in that run.

The atmospheric $\mathrm{CO}_{2}$ concentration increases from the pre-industrial level in the $0 \mathrm{x}$ Sensitivity and 1x Sensitivity cases by 391 and 442 ppmv, respectively. The difference is only 51 ppmv between the 0 x Sensitivity and 1 x Sensitivity cases. Cox, et al. (2000) and Friedlingstein, et al. (2001) obtained differences of about 250 and 100 ppmv, respectively in their models. Their year- 2100 warmings were 5.5 and $3 \mathrm{~K}$, respectively. The "carbon cycle feedback factor" is defined as the ratio of $\mathrm{CO}_{2}$ change when climate is changing to the $\mathrm{CO}_{2}$ change when climate is constant (Friedlingstein, et al., 2003). The implied net carbon cycle feedback factor in our simulations is 1.13 . The net carbon cycle feedback factors are 1.19 and 1.675 in Friedlingstein, et al. (2001) and Cox, et al. (2000), respectively. Therefore, our model shows the weakest feedback between climate and carbon cycle among the existing coupled climate and carbon cycle models. However, because of the nonlinear dependence of heterotrophic respiration on temperature (Lloyd and Taylor, 1994), the $\mathrm{CO}_{2}$ in the $2 \mathrm{x}$ Sensitivity case increases by $578 \mathrm{ppmv}$ and the carbon cycle feedback factor increases nonlinearly to 1.48. Atmospheric $\mathrm{CO}_{2}$ concentrations are 176 ppmv higher in the run with $8 \mathrm{~K}$ climate change than in the run with no climate change.

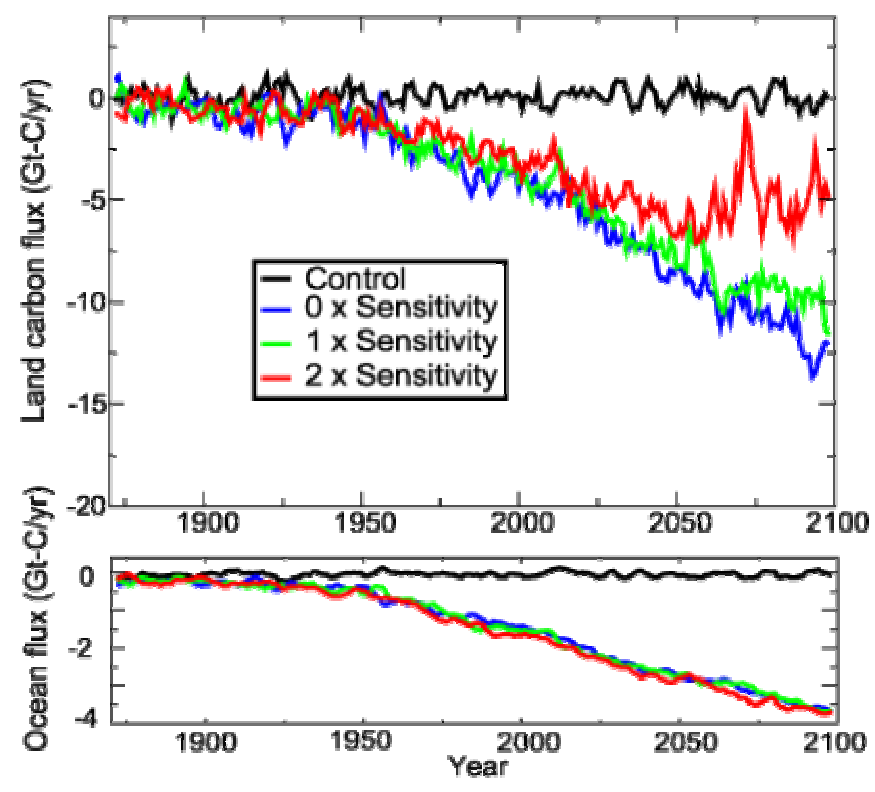


Figure 4 Evolution of the 5-yr running mean of global, annual flux of carbon from land to atmosphere (upper panel) and from ocean to atmosphere (lower panel).

The global and annual mean net land and ocean uptakes are shown in Fig.4. The model tends to slightly overestimate historical terrestrial carbon uptake estimates for the 1980s and 1990s based on observed intra-decadal trends in atmospheric $\mathrm{CO}_{2}$ and $\mathrm{O}_{2}$ (Prentice et al., 2001). The land uptake increases monotonically with time in the $0 \mathrm{x}$ Sensitivity case and it reaches values larger than $10 \mathrm{GtC}$ per year, by year 2100 , which is more than a third of the emission rate at that time. The effect of $\mathrm{CO}_{2}$ fertilization is probably exaggerated in these simulations because we do not consider factors other than limitation by sunlight, water, and carbon dioxide. Inclusion of other factors, such as nitrogen or phosphate limitation might diminish the magnitude of the response to added $\mathrm{CO}_{2}$ (Hungate, et al. 2003). Compared to similar models, IBIS also tends to simulate a higher fertilization effect (McGuire, et al, 2001).

Under the SRES A2 scenario, total emissions reach $29 \mathrm{GtC}$ per year at year 2100. Cumulative anthropogenic emissions for the period 1870 to 2100 amounts to $2200 \mathrm{GtC}$. The amounts taken up by land and ocean are shown in Fig.5. In the 0 x Sensitivity case, land takes up $1031 \mathrm{GtC}$, nearly 50 percent of the emissions (Fig. 5a). The uptake is reduced to 919 and $629 \mathrm{GtC}$ in the 1 x Sensitivity and 2 x Sensitivity runs, respectively. Therefore, land uptake decreases from 47 to $29 \%$ (1031 to $629 \mathrm{GtC})$ of the total emissions as the global temperature change increases from 0 to $8 \mathrm{~K}$ in our model. The HadCM3 modeling study showed a range of -5 to $34 \%(-100 \mathrm{GtC}$ to $650 \mathrm{GtC})$ of the $1900 \mathrm{GtC}$ emissions of the IS92a scenario for the same temperature range (Cox, et al., 2000; Friedlingstein, et al., 2003). Therefore, there is a large range of model projections of future land uptake in current coupled climate/carbon models. 


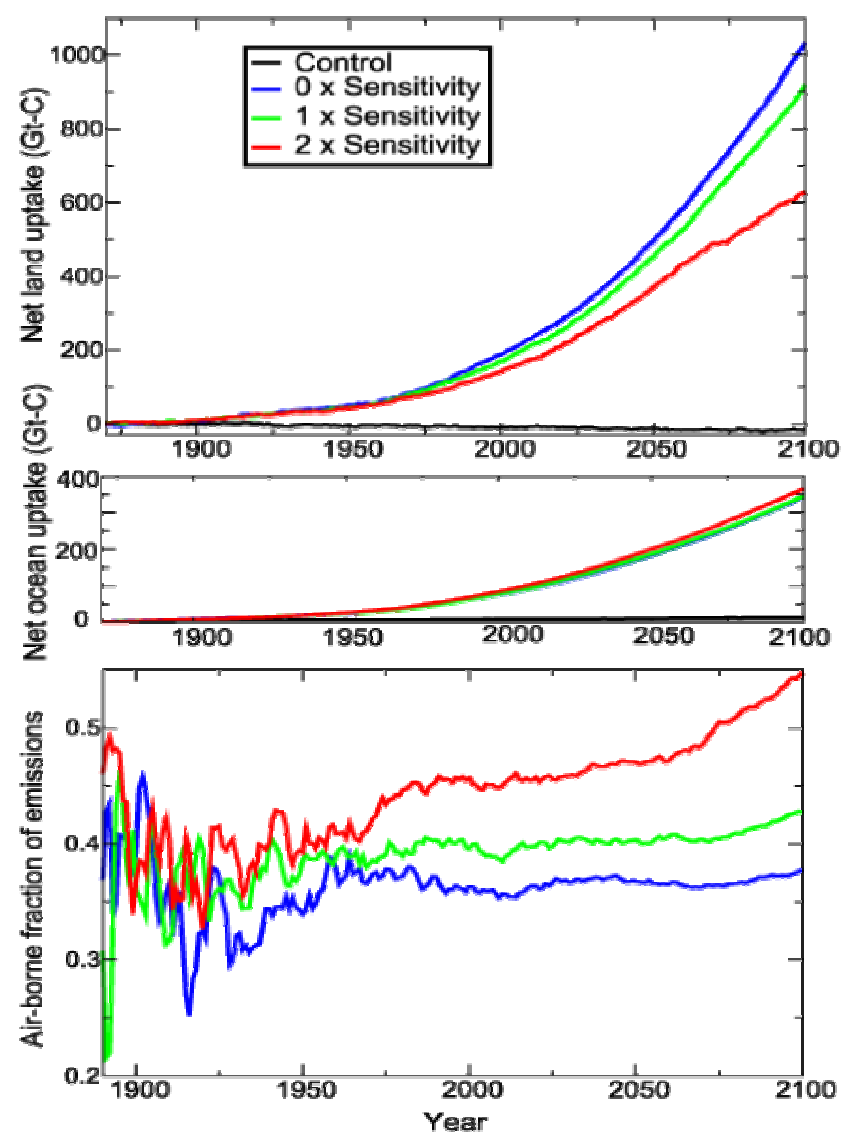

Figure 5 Evolution of cumulative carbon uptakes by land (upper panel) and oceans (middle panel) since the pre-industrial period. The airborne fraction of cumulative emissions is shown in the bottom panel.

The total ocean uptakes in our $0 \mathrm{x}$ Sensitivity, $1 \mathrm{x}$ Sensitivity and $2 \mathrm{x}$ Sensitivity cases differ little (Fig. 5b). The net uptake over the period 1870-2100 is around $350 \mathrm{GtC}$ in all the runs. Therefore, future ocean carbon uptake appears to be relatively insensitive to uncertainty in climate sensitivity in our model for specified $\mathrm{CO}_{2}$ emission scenarios. In agreement with our results, Cox, et al. (2000) and Friedlingstein, et al. (2001) obtained only modest sensitivity of the ocean carbon uptake to climate change in the HadCM3 and IPSL models.

The fraction of the cumulative anthropogenic emissions that remains in the atmosphere at any time since year 1870 depends on the climate change (Fig. 5c). Since the averaging time interval increases with time, the fractions exhibit little variability in the later periods and the curves become smooth towards the end of simulations. The fractions from all the runs are close to each other until year 1970. After that, they diverge from each other. In the $0 \times$ Sensitivity case, only $37 \%$ of the total emissions remain in the atmosphere by year 2100. This fraction reaches $43 \%$ and $55 \%$ in the $1 \times$ Sensitivity and $2 \times$ Sensitivity cases, respectively. Therefore, the fraction of emissions that remains in the atmosphere increases with warming primarily because the land uptake declines with warming. 


\section{Model Improvements for Future Studies}

The IBIS terrestrial biosphere model has not allowed for agriculture or other aspects of non-natural land cover or land use change. Moreover, it has been restricted to running on the same coarse spatial grid as the atmospheric model, thus limiting its ability to simulate land surface heterogeneity. We have modified IBIS to relax these limitations, thus allowing for increased realism. Specifically, each land point can be represented a multiplicity of times. This allows for a variety of vegetation types, enabling one to study anthropogenic effects. Alternatively, the multiplicity of land points can be used to simulate the effects of a finer land grid.

This study uses the NCAR-DOE developed PCM2 atmosphere-ocean model as our core climate model. A newer, more standardized model has recently become available, the NCAR CCSM3. We have combined IBIS with CCSM3 as a first step toward creation of a new climate/carbon model. The coupling between IBIS and the atmospheric component is through the flux coupler. This enables IBIS to have a resolution separate from that of the atmosphere.

\section{Exit Plan and Return to Laboratory}

The return to the Laboratory of this project is in the category of great science, since we are enhancing an existing leading edge simulation capability that has high international visibility. Our results are to appear in several leading journals (Tellus, Geophysical Research Letters). Our success has led to a higher visibility within DOE and a broader collaboration with scientists at Oak Ridge and Los Alamos National Laboratories in the area of climate/carbon modeling.

Based on capabilities achieved in this LDRD project, in late FY04, we were awarded funding from DOE to provide delivery of an OMB directive of an integrated climate/carbon/sulfur modeling capability. Those funds, coupled with other existing DOE projects, are being used to accomplish this DOE deliverable by the end of FY05.

\section{Summary}

We have used our integrated climate and carbon modeling capability to perform breakthrough studies of the climate. Using an advanced computational model developed under a recent Strategic Initiative, we have performed two major studies - namely the effects of $\mathrm{CO}_{2}$-fertilized vegetation on global climate and carbon dynamics, and the effect of climate sensitivity on carbon cycle feedback. We have also begun development of a next-generation climate/carbon model.

\section{References}

Cox, P.M., R.A. Betts, C.D. Jones, S.A. Spall and I.J. Totterdell (2000), Acceleration of global warming due to carbon-cycle feedbacks in a coupled climate model, 
Nature, 408, 184-187.

Cramer, W., et al. (2001), Global response of terrestrial ecosystem structure and function to $\mathrm{CO}_{2}$ and climate change: results from six dynamic global vegetation models, Global Change Biology, 7, 357-373.

Dukowicz, J.K., and R.D. Smith (1994), Implicit free-surface method for the Bryan-CoxSemtner ocean model, J. Geophys. Res., 99, 7991-8014.

Farquhar, G.D., S.V. Caemmerer and J.A. Berry (1980), A biochemical-model of photosynthetic $\mathrm{CO}_{2}$ assimilation in leaves of C-3 species, Planta, 149, 78-90.

Foley, J.A., et al. (1996), An integrated biosphere model of land surface processes, terrestrial carbon balance, and vegetation dynamics, Global Biogeochem. Cycles, $10,603-628$.

Friedlingstein, P, et al. (2001), Positive feedback between future climate change and the carbon cycle, Geophys. Res. Lett., 28, 1543-1546.

Friedlingstein, P., J.-L. Dufresne, P.M. Cox and P. Rayner (2003), How positive is the feedback between climate change and the carbon cycle? Tellus, 55B, 692-700.

Giardina, C.P. and M.G. Ryan (2000), Evidence that decomposition rates of organic carbon in mineral soil do not vary with temperature, Nature, 404, 858-861.

Govindasamy, B., S. Thompson, A. Mirin, M. Wickett, K. Caldeira and C. Delire (2004), Increase of carbon cycle feedback with climate sensitivity; Results from a coupled climate and carbon cycle model, Tellus B (in press).

Houghton, R.A (2003), Revised estimates of the annual net flux of carbon to the atmosphere from changes in land use and land management 1850-2000, Tellus, 55B, 378-390.

Houghton, J.T. et al., (Eds.) (2001), Climate Change 2001, The Scientific Basis, Cambridge Univ. Press, Cambridge.

Hungate, B.A., J.S. Dukes, M.R. Shaw, Y. Luo and C.B. Field (2003), Nitrogen and climate change, Science, 302, 1512-1513.

Joos, F., et al. (2001), Global warming feedbacks on terrestrial carbon uptake under the Intergovernmental Panel on Climate Change (IPCC) emission scenarios, Global Biogeochemical Cycles, 15, 891-907.

Kheshgi, H.S. (2004), Ocean carbon sink duration under stabilization of atmospheric $\mathrm{CO}_{2}$ - A 1000 year time scale, Geophys. Res. Lett. (in press).

Kiehl, J.T., J.J. Hack, G.B. Bonan, B.Y. Boville, B.P. Briegleb, D.L. Williamson and P.J. Rasch (1996), Description of the NCAR Community climate Model (CCM3). NCAR Tech. Note. NCAR/TN-420+STR.

Kirschbaum, M.U.F. (2000), Will changes in soil organic carbon act as a positive or negative feedback on global warming? Biogeochemistry, 48, 21-51.

Kucharik, C.J., et al (2000), Testing the performance of a Dynamic Global Ecosystem Model: Water balance, carbon balance, and vegetation structure, Global Biogeochem. Cycles 14 (3), 795-825.

Lloyd, J. and J.A. Taylor (1994), On the temperature-dependence of soil respiration, Functional Ecology, 8, 315-323.

Maier-Reimer, E. (1993), Geochemical cycles in an ocean general-circulation model preindustrial tracer distributions, Global Biogeochemical Cycles, 7(3), 645-677.

Maltrud, M. E., R.D. Smith, A.J. Semtner and R.C. Malone (1998), Global eddyresolving ocean simulations driven by 1985-1995 atmospheric winds. J. Geophys. 
Res. 103, 30825-30853.

Marland, G., T. Boden and R. Andres (2000), Global, regional, and national annual $\mathrm{CO}_{2}$ emissions from fossil-fuel burning, cement production and gas flaring: 17511999, CDIAC NDP-030, Carbon Dioxide Information Analysis Center, Oak Ridge National Laboratory, Oak Ridge, Tennessee.

McGuire, A.D., S. Sitch, J.S. Clein, R. Dargaville, G. Esser, J. Foley, M. Heimann, F. Joos, J. Kaplan, D.W. Kicklighter, R.A. Meier, J.M. Melillo, B. Moore III, I.C. Prentice, N. Ramankutty, T. Reichenau, A. Schloss, H. Tian, L.J. Williams and U. Wittenberg (2001), Carbon balance of the terrestrial biosphere in the twentieth century: Analyses of $\mathrm{CO} 2$, climate and land-use effects with four process-based ecosystem models. Global Biogeochemical Cycles 15, 183-206.

Meehl, G.A., W.M. Washington, J.M. Arblaster and A.X. Hu (2004), Factors affecting climate sensitivity in global coupled models, J. Climate 17, 1584-1596.

Najjar, R.G. and J.C. Orr (1999), Biotic How-To, Revision 1.7, Ocean Carbon-cycle Model Intercomparison Project (OCMIP), http://www.ipsl.jussieu.fr/OCMIP/phase2/simulations/Biotic/HOWTOBiotic.html

Prentice, I.C., G.D. Farquhar, M.J.R. Fasham, M.L. Goulden, M. Heimann, and coauthors (2001), Climate Change 2001: The Scientific Basis: Contribution of Working Group I to the Third Assessment Report of the IPCC, J.T. Houghton et al. (Eds.) Cambridge University Press, UK, pp. 183-237.

Sabine, C.L., et al. (2004), The oceanic sink for anthropogenic $\mathrm{CO}_{2}$, Science, 305, 367371.

Sarmiento, J.L, M.C. Hughes, R.J. Stouffer and S. Manabe (1998), Simulated response of the ocean carbon cycle to anthropogenic climate warming, Nature, 393, 245-249.

Thompson, S., B. Govindasamy, A. Mirin, M. Wickett, K. Caldeira and C. Delire (2004), Quantifying CO2-fertilized vegetation on the global climate and carbon dynamics, Geophys. Res. Lett. (in press).

Tjoelker, M.G., J. Oleksyn and P.B. Reich (2001), Modelling respiration of vegetation: evidence for a general temperature-dependent Q(10), Global Change Biology, 7, 223-230.

Washington, W.M., et al. (2000), Parallel climate model (PCM) control and transient simulations, Climate Dynamics, 16, 755-774. 